\title{
Anxiety and Adaptation of Behavior in Pregnant Zhuang Women During the COVID-I9 Pandemic: A Mixed-Mode Survey
}

This article was published in the following Dove Press journal: Risk Management and Healthcare Policy

\author{
Yuan $\mathrm{Ge}^{\prime}$ \\ Chunhong Shi $\mathbb{D}^{2}$ \\ Bin Wu' \\ Yannan $\mathrm{Liu}^{3}$ \\ Ling Chen' \\ Yuegui Deng ${ }^{4}$ \\ 'School of Nursing, Guangxi University of \\ Chinese Medicine, Nanning, 530200, \\ People's Republic of China; ${ }^{2}$ School of \\ Nursing, Xiangnan University, Chenzhou, \\ 423000, People's Republic of China; \\ ${ }^{3}$ Nursing School, Hunan University of \\ Medicine, Huaihua, 418000, People's \\ Republic of China; ${ }^{4}$ Nursing Department, \\ The First Affiliated Hospital of Guangxi \\ University of Chinese Medicine, Nanning, \\ 530022, People's Republic of China
}

Purpose: This study explored the impact of COVID-19 on the mental health and adaptation of behavior of Zhuang women in China to provide more specific guidance for the social and medical practice of pregnant women during public health emergencies.

Participants and Methods: This cross-sectional study recruited 446 pregnant Zhuang women from obstetric outpatient clinics in four tertiary hospitals and online maternity schools in Nanning, Guangxi, between February 24 and March 1, 2020. Self-designed questionnaires and the Self-Rating Anxiety Scale were used.

Results: During the COVID-19 pandemic, the prevalence rate of anxiety among women was $36.77 \%$, and some adaptation of behavior was observed. Logistic regression analysis showed that pregnant women who had an annual household income of less than $\$ 7,000$, were primiparous, went out for prenatal examination, wanted to self-monitor during pregnancy but did not know how to do it, believed that they should be strictly isolated at home and cancel prenatal examinations, and expected to receive pregnancy healthcare through teleconsultation services showed a higher risk of anxiety. Nevertheless, pregnant Zhuang women who were 22-35 years old, undergraduate-educated, and in their second trimester were less likely to suffer from anxiety.

Conclusion: The COVID-19 pandemic has a significant psychological impact on pregnant women from ethnic minorities. Factors related to quarantine and social isolation policies appear to drive changes in behaviors and anxiety disorders. Multidisciplinary mental health services and culturally sensitive interventions are necessary for minority pregnant women, especially for low-income primiparous women in the first or third trimester.

Keywords: pregnant women, minority, psychological, behavior, coronavirus disease 2019

\section{Introduction}

Coronavirus disease (COVID-19) is a highly infectious disease with a rapid increase in cases and deaths, and its ongoing outbreak has been declared a global public health emergency. ${ }^{1}$ Its rapid spread aroused concern among the Chinese government, health authorities, and the public. ${ }^{2}$ Strict measures were adopted across China to control the outbreak, including locking-down cities (especially in the Hubei Province), advising residents to stay at home, and implementing quarantine policies to reduce the chance of transmission. ${ }^{3}$ As a vulnerable group, pregnant women attracted special attention during the pandemic.

Psychological distress and disorders are particularly prevalent among pregnant women. Even in normal times, the prevalence of anxiety disorder in pregnant women
Correspondence: Chunhong Shi

School of Nursing, Xiangnan University, 889 Chenzhou Avenue, Suxian District, Chenzhou, 423000, Hunan, People's Republic of China

Tel +86 I5907354840

Fax +86-735-2325007

Email shichunhong@xnu.edu.cn
Risk Management and Healthcare Policy 202 I:|4 |563-I573 
was reported to be as high as $17 \%,{ }^{4}$ and the overall prevalence of anxiety clinical diagnosis was nearly $15.2 \% .{ }^{5}$ The unique needs and challenges in pregnancy can increase anxiety and stress levels in women. However, the COVID-19 pandemic may worsen psychological distress in pregnant women. Thapa and colleagues ${ }^{6}$ supposed that the fear of infection and the exceptional quarantine measures might impose additional pressure on women's mental health. An online survey in Canada showed that $72 \%$ of women during pregnancy or within one year after delivery suffered from moderate to high anxiety. ${ }^{7}$ Corbett's survey in Ireland identified that more than $50 \%$ of women in the second and third trimester of pregnancy have significant health-related anxiety. ${ }^{8}$ Evidently, apart from a negative impact on prenatal events, ${ }^{9}$ the psychological impact of COVID-19 on pregnant women might be greater. ${ }^{10}$ However, suffering from psychological distress not only has a great impact on the growth and development of the fetus, but also affects the physical and mental health of both the mother and fetus, as well as the stability of the family. ${ }^{11,12}$ Thus, the psychological problems of pregnant women during the pandemic cannot be neglected. In addition, pregnant women also experienced behavioral changes in response to the threat of COVID-19. For example, Corbett et $\mathrm{al}^{8}$ reported that approximately one-third of pregnant women isolated themselves, started to work from home, and almost half of the women changed their transportation methods. In China, previous studies reported that pregnant women went out less, and about two-fifths of pregnant women did not undergo prenatal examination or did not have antenatal visits on time after the peak of the outbreak of COVID-19. ${ }^{13}$ Similarly, Yue et al ${ }^{14}$ found that pregnant women take protective measures such as wearing masks, washing hands frequently, cleaning, and disinfecting their homes to avoid virus infection.

China is composed of the Han ethnic group and 55 ethnic minorities, with an ethnic minority population of approximately 112 million, accounting for $8.40 \%$ of the total population. ${ }^{15}$ The fertility rate among ethnic minorities has been higher than the national average for a long time. ${ }^{16,17}$ Previous studies have shown that pregnant women from ethnic minorities face several barriers related to language, limited health care resources, and financial issues when accessing pregnancy services. ${ }^{18}$ Additionally, the battle against COVID-19 has mobilized most of the medical force in China, causing pressure on the provision of basic medical services, such as perinatal and mental health support. ${ }^{19}$ These factors have challenged the availability of routine maternity health care services for ethnic minority pregnant women and affect their mental health.
Since the outbreak of COVID-19, a growing body of literature has assessed the impact of COVID-19 on pregnancy. The majority of the studies focused on confirmed cases of COVID-19 among pregnant women. ${ }^{20,21}$ Only a few reports have mentioned the psychological distress and needs of healthy pregnant women. However, these limited data mainly focus on major ethnic groups. Information regarding the mental health of ethnic minority pregnant women, especially during the most difficult period of the COVID-19 outbreak in China, is still scarce. Zhuang people are the most populous ethnic minority in China, mainly residing in the Guangxi Zhuang Autonomous Region; their estimated birth rate was 13.31 per 1000 in $2019 .^{22}$ This study aimed to 1) investigate the behavioral changes and anxiety status of pregnant Zhuang women in the Guangxi Zhuang Autonomous Region during the most challenging period of the COVID-19 outbreak in China, and 2) explore the risk factors associated with anxiety in pregnancy.

\section{Participants and Methods}

A cross-sectional, descriptive study of pregnant women was conducted anonymously via face-to-face and online questionnaire surveys with pregnant women at obstetric outpatient clinics in four tertiary hospitals and online maternity schools in Nanning, Guangxi Province, China.

\section{Participants}

Participants were recruited through cluster sampling for the face-to-face survey and snowball sampling for the online survey from February 24 to March 1, 2020. The inclusion criteria were as follows: 1) being a Zhuang healthy pregnant woman (positive HCG test and B-ultrasound showing intrauterine pregnancy), 2) maternal age $>18$ and $<60$ years, 3) being able to independently complete the questionnaire, and 4) providing consent to participate in the study. Women with ectopic pregnancy, pregnancy complications, abnormal fetuses, respiratory symptoms, or a potential diagnosis of COVID-19 were excluded. The sample size in this study was determined by the formula for sample size estimation in prevalence studies recommended in Lwanga's book. ${ }^{23}$

$$
n=\frac{z_{\alpha / 2}^{2} P(1-P)}{\delta^{2}}
$$

According to a previous survey, the prevalence of anxiety during pregnancy was $15 \%-23 \%$ at normal times. ${ }^{24}$ However, it is suspected that the prevalence of anxiety in the population during the COVID-19 pandemic is higher than that in non-epidemic times; thus, we set the 
expected prevalence (ie, $\mathrm{p}$ ) at $40 \%$. To obtain $\mathrm{z}$ as $95 \%$ confidence of 1.96 , and $\delta$ as an error tolerance of 0.05 , a sample size of 369 was required. Assuming a 15\% loss of the sample, the actual sample size requirement was 443 . Finally, 446 valid questionnaires were obtained to meet the sample size requirements.

\section{Survey Tools}

The self-report questionnaire was developed by the principal researcher and revised by a psychology professor and an obstetrics professor. The final version of this questionnaire was confirmed after a pretest with 15 participants not included in this study. It consists of the following three parts:

(1) General information regarding the pregnant women: age, education, race, occupation, annual household income, marital status, gestational age, gravidity and parity history, and number of children.

(2) Adaptations in behavior during COVID-19 related to going out, reasons for going out, measures for prevention and control of infection, prenatal examinations, attitude toward prenatal examinations, selfmonitoring during pregnancy, and expected access to pregnancy healthcare.

(3) The Chinese version of the Self-Rating Anxiety Scale (SAS) was revised by Wang and Chi in 1984, ${ }^{25}$ based on Zung's ${ }^{26}$ English version, which has been widely used and proven to have good reliability and validity in the assessment of pregnant women. ${ }^{27}$ This scale includes 20 self-report questions used to evaluate participants' feelings in the last seven days. The total score is equal to the sum of the scores of the 20 items multiplied by 1.25, and ranges from 25 to 100 . The higher the total score, the higher the anxiety level. According to the Chinese national norm, a cut-off score of 50 is recommended; scores between 25 and 49, 50-59, 60-69, and $\geq 70$ indicate a normal range, mild anxiety, moderate anxiety, and severe anxiety, respectively. ${ }^{28}$ Cronbach's alpha in this study was 0.90 .

\section{Data Collection}

The online survey was administered via the Questionnaire Star platform (https://www.wjx.cn, Changsha Ranxing Science and Technology, Shanghai, China), a user-friendly, popular application tool for all types of surveys. The respondents were recruited through online maternity schools (offering antenatal, perinatal, and postpartum health care knowledge and real-time online consultation and interaction), and a link was provided for them to participate in the survey. After reading the information regarding the study's purpose, content, significance, and risks and benefits on the first page, participants provided their informed consent and proceeded with the online questionnaire. Only one submission was allowed for each participant. A total of 189 web-based questionnaires were completed. The face-to-face questionnaire survey was conducted by outpatient obstetric nurses in four tertiary hospitals in Nanning, who had been trained in the survey methodology. After carefully screening the information regarding pregnant women in the clinic, the investigators distributed the paper-version questionnaires to the eligible respondents. The women anonymously filled out the questionnaire following uniform instructions after signing the informed consent form. We obtained 391 questionnaires in obstetrics clinics (108 copies from the First Affiliated Hospital of Guangxi Medical University, 104 copies from the First Affiliated Hospital of Guangxi University of Chinese Medicine, 92 copies from Ruikang Hospital, affiliated to Guangxi University of Chinese Medicine, and 87 copies from Nanning Chinese Medicine Hospital). Ultimately, 580 responses were obtained. After excluding 134 questionnaires that indicated non-Zhuang ethnicity, complicated pregnancy diseases, or illogical answers, 446 valid questionnaires (76.90\%) were retained. Figure 1 shows a flow diagram of the data sampling. Each questionnaire took approximately 5-10 $\mathrm{min}$ to complete.

\section{Ethical Considerations}

Participants voluntarily and anonymously completed the questionnaire after providing informed consent and were allowed to withdraw their participation at any time. After completing the investigation, they would obtain 5 to 10 Chinese RMB (roughly equivalent to 0.70-1.40 USD) and tips on the health care of pregnant women during the epidemic. The responses were strictly confidential and were stored on a personal computer.

\section{Data Analysis}

Data obtained from the survey were analyzed using SPSS software (version 25.0; IBM Corp., Armonk, NY, USA). Continuous variables were described as mean \pm standard deviation, and categorical variables were expressed as 


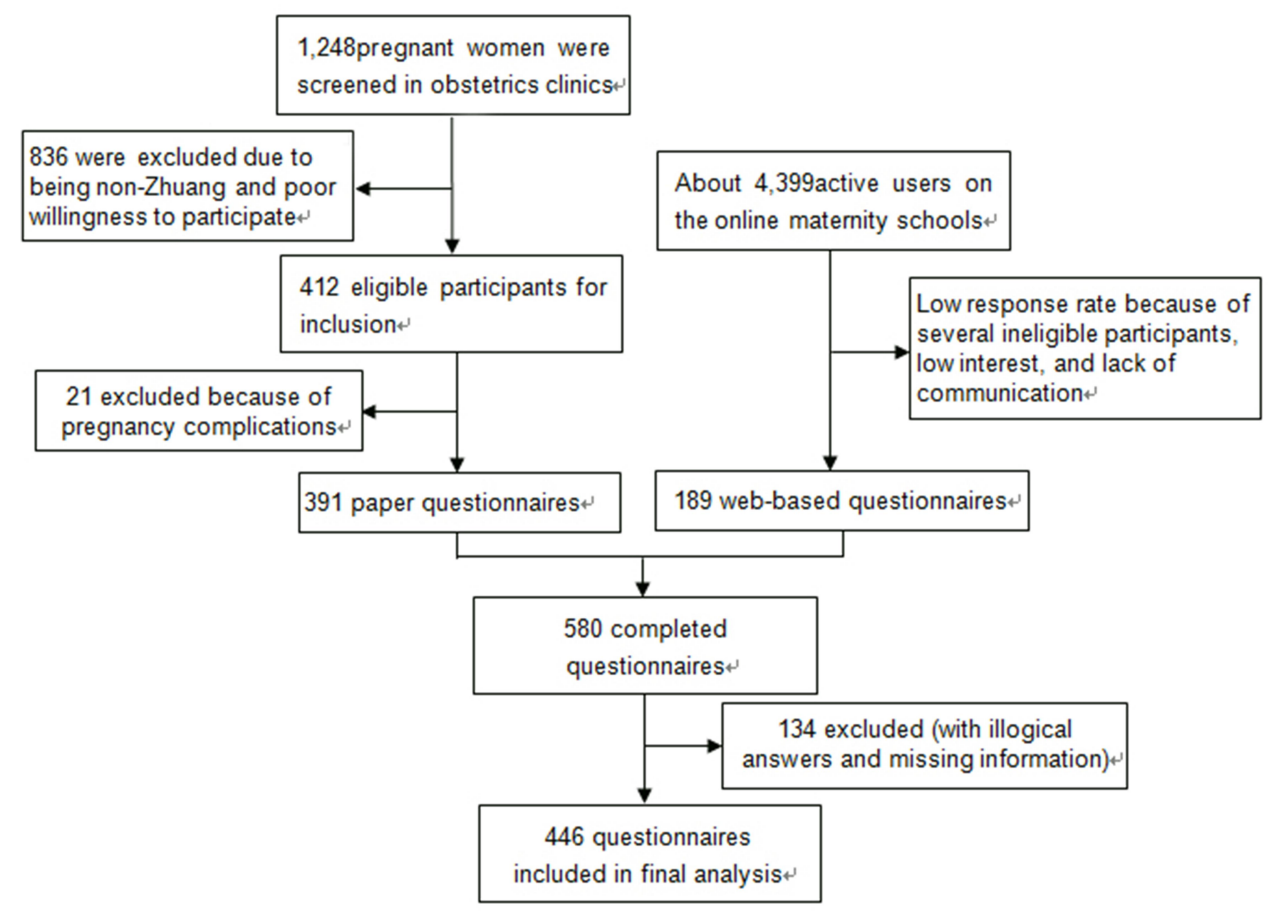

Figure I The flow diagram of data sampling.

frequency and percentage. For univariate analyses, independent samples $t$-test and chi-square tests were used to analyze differences between continuous and categorical variables, respectively. Multivariate logistic regression models were used to evaluate the association between different factors and anxiety symptoms. The statistical significance level was set at $P<0.05$.

\section{Results}

\section{Demographic and Obstetric Characteristics of Participants}

Among the 446 eligible pregnant Zhuang women, most participants were between 22 and 35 years old $(80.49 \%$, $\mathrm{N}=359)$, had full-time jobs $(83.18 \%, \mathrm{~N}=371)$, were married $(92.15 \%, \mathrm{~N}=411)$, and had an annual household income of more than $\$ 7000(76.68 \%, \mathrm{~N}=342)$. More than half of them $(51.12 \%, \mathrm{~N}=228)$ had received undergraduate education. The proportions of the first trimester, second trimester, and third trimester of pregnancy were $10.54 \%(\mathrm{~N}=47), 35.20 \%$ $(\mathrm{N}=157)$, and $54.26 \%(\mathrm{~N}=242)$, respectively. Primiparous and multiparous women accounted for approximately half (50.90\%, $\mathrm{N}=227$ vs $49.10 \%, \mathrm{~N}=219$ ) of the participants. Overall, $60.54 \%(\mathrm{~N}=270)$ of the pregnant women had no children at present, and the rest had one $(36.10 \%, \mathrm{~N}=161)$ or more $(3.36 \%, N=15)$. See Table 1 .

\section{Prevalence of Pregnant Anxiety and Adaptations in Participants' Behavior}

The average SAS score of the respondents was 47.29 \pm 9.19 , and $36.77 \%(\mathrm{~N}=164)$ met the cut-off point for anxiety. Of these, $25.34 \%(\mathrm{~N}=113)$ had mild anxiety, $10.09 \%(\mathrm{~N}=45)$ had moderate anxiety, and $1.35 \%(\mathrm{~N}=6)$ had severe anxiety. $35.43 \%$ of pregnant women $(\mathrm{N}=158)$ reported that they had never gone out since the COVID-19 pandemic had begun, $41.03 \%(\mathrm{~N}=183)$ had gone out $1-6$ times, and $23.54 \%(\mathrm{~N}=105)$ had gone out six times or more. Among the women who had gone out, $86.11 \%$ (N $=248)$ often wore masks, and only $8.97 \%(\mathrm{~N}=40)$ wore masks occasionally, mainly due to prenatal examinations (47.22\%, $\mathrm{N}=136)$ and shopping or eating $(45.14 \%, \mathrm{~N}=$ $130)$; only $22(4.93 \%)$ women went out to visit relatives and friends or for other reasons. More than half of the participants $(56.28 \%, \mathrm{~N}=251)$ affirmed that they could and would conduct self-monitoring during pregnancy (such as monitoring abdominal pain, fetal movement, uterine contraction, vaginal bleeding, etc.), $37 \%(\mathrm{~N}=165)$ wanted to practice self-monitoring but did not know how to do it, and only a few of them $(6.73 \%, \mathrm{~N}=30)$ reported that they did not care about it. Most of the women $(63.23 \%, \mathrm{~N}=282)$ believed that they needed to delay prenatal examinations because of the COVID-19 
Table I Participants' Demographic and Obstetric Characteristics, Adaptations in Behavior, and Differences in the Self-Rating Anxiety Scale (SAS) Scores $(N=446)$

\begin{tabular}{|c|c|c|c|c|c|}
\hline \multicolumn{2}{|l|}{ Variables } & \multirow{2}{*}{$\begin{array}{l}\text { N (\%) } \\
55(12.33) \\
359(80.49) \\
32(7.17)\end{array}$} & \multirow{2}{*}{$\begin{array}{c}\text { SAS (M } \pm \text { SD) } \\
54.75 \pm 10.02 \\
45.94 \pm 8.26 \\
49.57 \pm 11.14\end{array}$} & \multirow{2}{*}{$\begin{array}{c}\mathbf{t} / \mathbf{F} \\
25.489\end{array}$} & \multirow{2}{*}{$\begin{aligned} P \text {-value } \\
0.000\end{aligned}$} \\
\hline Age (years) & $\begin{array}{l}\text { Under } 22 \\
22-35 \\
\text { Over } 35\end{array}$ & & & & \\
\hline $\begin{array}{l}\text { Educational } \\
\text { background }\end{array}$ & $\begin{array}{l}\text { High school or below } \\
\text { Undergraduate } \\
\text { Postgraduate }\end{array}$ & $\begin{array}{l}130(29.14) \\
228(51.12) \\
88(19.73)\end{array}$ & $\begin{array}{c}53.09 \pm 8.53 \\
44.97 \pm 7.63 \\
44.73 \pm 10.07\end{array}$ & 43.504 & 0.000 \\
\hline Occupation & $\begin{array}{l}\text { Full-time work } \\
\text { Part-time work } \\
\text { Does not work }\end{array}$ & $\begin{array}{l}37 \mid(83.18) \\
47(10.54) \\
28(6.28)\end{array}$ & $\begin{array}{l}46.87 \pm 9.03 \\
50.07 \pm 9.88 \\
48.21 \pm 9.49\end{array}$ & 2.722 & 0.067 \\
\hline Marital status & $\begin{array}{l}\text { Single } \\
\text { Married } \\
\text { Divorced }\end{array}$ & $\begin{array}{l}26(5.83) \\
411(92.15) \\
9(2.02)\end{array}$ & $\begin{array}{c}47.12 \pm 10.40 \\
47.28 \pm 9.09 \\
48.06 \pm 11.08\end{array}$ & 0.036 & 0.965 \\
\hline $\begin{array}{l}\text { Annual } \\
\text { household } \\
\text { income }\end{array}$ & $\begin{array}{l}\leq \$ 7,000 \\
>\$ 7,000\end{array}$ & $\begin{array}{l}104(23.32) \\
342(76.68)\end{array}$ & $\begin{array}{l}50.97 \pm 8.58 \\
46.17 \pm 9.09\end{array}$ & 4.782 & 0.000 \\
\hline Trimester & $\begin{array}{l}\text { First trimester } \\
\text { Second trimester } \\
\text { Third trimester }\end{array}$ & $\begin{array}{l}47(10.54) \\
157(35.20) \\
242(54.26)\end{array}$ & $\begin{array}{c}47.31 \pm 10.10 \\
45.72 \pm 7.11 \\
48.30 \pm 10.05\end{array}$ & 3.790 & 0.023 \\
\hline Parity & $\begin{array}{l}\text { Primiparous } \\
\text { Multiparous }\end{array}$ & $\begin{array}{l}227(50.90) \\
219(49.10)\end{array}$ & $\begin{array}{l}50.01 \pm 9.60 \\
44.47 \pm 7.82\end{array}$ & 6.671 & 0.000 \\
\hline $\begin{array}{l}\text { Number of } \\
\text { children }\end{array}$ & $\begin{array}{l}\text { None } \\
1 \\
2 \text { or more }\end{array}$ & $\begin{array}{l}270(60.54) \\
161(36.10) \\
15(3.36)\end{array}$ & $\begin{array}{l}49.28 \pm 9.45 \\
44.20 \pm 7.79 \\
44.50 \pm 9.10\end{array}$ & 17.268 & 0.000 \\
\hline $\begin{array}{l}\text { Frequency of } \\
\text { going out }\end{array}$ & $\begin{array}{l}\text { None } \\
\text { I-6 times } \\
\text { Over } 6 \text { times }\end{array}$ & $\begin{array}{l}158(35.43 \%) \\
183(41.03 \%) \\
105(23.54 \%)\end{array}$ & $\begin{array}{l}47.88 \pm 9.90 \\
49.10 \pm 7.94 \\
43.25 \pm 8.95\end{array}$ & $|4.89|$ & 0.000 \\
\hline $\begin{array}{l}\text { Primary reason } \\
\text { for going out }\end{array}$ & $\begin{array}{l}\text { None } \\
\text { Prenatal examination } \\
\text { Shopping or eating } \\
\text { Visiting relatives and } \\
\text { friends or other reasons }\end{array}$ & $\begin{array}{l}158(35.43 \%) \\
136(30.49 \%) \\
130(29.15 \%) \\
22(4.93 \%)\end{array}$ & $\begin{array}{l}47.88 \pm 9.90 \\
48.60 \pm 9.58 \\
45.03 \pm 7.61 \\
48.30 \pm 7.99\end{array}$ & 3.930 & 0.009 \\
\hline $\begin{array}{l}\text { Wearing mask } \\
\text { when going out }\end{array}$ & $\begin{array}{l}\text { Never } \\
\text { Occasionally } \\
\text { Always }\end{array}$ & $\begin{array}{l}158(35.43 \%) \\
40(8.97 \%) \\
248(55.60 \%)\end{array}$ & $\begin{array}{l}47.88 \pm 9.90 \\
49.00 \pm 6.94 \\
46.64 \pm 9.00\end{array}$ & 1.647 & 0.194 \\
\hline $\begin{array}{l}\text { Self-monitoring } \\
\text { during } \\
\text { pregnancy }\end{array}$ & $\begin{array}{l}\text { Can and do } \\
\text { Want, but do not know } \\
\text { how to do } \\
\text { Do not care }\end{array}$ & $\begin{array}{l}251(56.28 \%) \\
165(37.00 \%) \\
30(6.73 \%)\end{array}$ & $\begin{array}{l}45.30 \pm 8.44 \\
50.76 \pm 9.01 \\
44.83 \pm 10.67\end{array}$ & 20.303 & 0.000 \\
\hline $\begin{array}{l}\text { Attitude } \\
\text { toward } \\
\text { prenatal } \\
\text { examinations }\end{array}$ & $\begin{array}{l}\text { Necessary, and attended } \\
\text { regularly } \\
\text { Necessary, but } \\
\text { temporarily postponed } \\
\text { Determinedly stayed at } \\
\text { home and canceled } \\
\text { prenatal examinations }\end{array}$ & $\begin{array}{l}139(31.17 \%) \\
282(63.23 \%) \\
25(5.61 \%)\end{array}$ & $\begin{array}{l}45.48 \pm 6.28 \\
47.66 \pm 10.22 \\
53.15 \pm 7.65\end{array}$ & 8.286 & 0.000 \\
\hline
\end{tabular}

(Continued) 
Table I (Continued).

\begin{tabular}{|c|c|c|c|c|c|}
\hline \multicolumn{2}{|l|}{ Variables } & N (\%) & SAS (M $\pm S D)$ & $\mathbf{t} / \mathbf{F}$ & $P$-value \\
\hline $\begin{array}{l}\text { Expected } \\
\text { access to } \\
\text { pregnancy } \\
\text { healthcare }\end{array}$ & $\begin{array}{l}\text { Regular obstetric clinic } \\
\text { visits } \\
\text { Teleconsultation services } \\
\text { Home visits by } \\
\text { obstetrician }\end{array}$ & $\begin{array}{l}57(\mid 2.78 \%) \\
22 \mid(49.55 \%) \\
168(37.67 \%)\end{array}$ & $\begin{array}{l}46.82 \pm 7.82 \\
48.83 \pm 9.54 \\
45.42 \pm 8.83\end{array}$ & 6.811 & 0.001 \\
\hline $\begin{array}{l}\text { Impact of } \\
\text { COVID-19 on } \\
\text { personal life }\end{array}$ & $\begin{array}{l}\text { Huge } \\
\text { Average } \\
\text { Small }\end{array}$ & $\begin{array}{l}38 \mathrm{I}(85.43 \%) \\
36(8.07 \%) \\
29(6.50 \%)\end{array}$ & $\begin{array}{c}47.93 \pm 8.44 \\
45.73 \pm 13.28 \\
40.78 \pm 10.07\end{array}$ & 9.055 & 0.000 \\
\hline \multicolumn{2}{|l|}{ Total } & 446 & \multicolumn{3}{|c|}{$47.29 \pm 9.19$} \\
\hline
\end{tabular}

pandemic, $31.17 \%(\mathrm{~N}=139)$ believed that prenatal examinations had to be conducted regularly, and only a few $(5.61 \%, \mathrm{~N}=25)$ believed that they should be strictly isolated at home and cancel prenatal examinations. In terms of access to maternal healthcare services, almost half $(49.55 \%, \mathrm{~N}=221)$ of the respondents hoped that healthcare institutions would provide teleconsultation services (eg, via telephone and Internet), followed by home visits by obstetricians $(37.67 \%, \mathrm{~N}=168)$ and regular obstetric clinic visits $(12.78 \%, \mathrm{~N}=57)$. The majority $(85.43 \%, \mathrm{~N}=381)$ of pregnant women reported that the COVID-19 pandemic had a huge impact on their personal lives, and few of them believed that the impact was average and minor. Table 1 shows the data regarding the behavioral adaptations of the participants.

\section{Univariate Analysis of Factors Associated with Anxiety}

Univariate analysis showed that age, educational background, annual household income, trimester, parity, number of children, frequency of going out, primary reason for going out, self-monitoring during pregnancy, attitude toward prenatal examinations, expected access to pregnant healthcare, and the impact of COVID-19 on personal life were significantly correlated with anxiety scores $(P<$ 0.05) (see Table 1).

\section{Anxiety Risk Factors Among Participants}

In the multivariate logistic regression analysis (Table 2), pregnant women who had an annual household income of less than $\$ 7,000(\mathrm{OR}=2.406,95 \%$ CI: $0.320,1.435$, $P=0.002$ ), were primiparous (OR $=7.135,95 \% \mathrm{CI}: 1.084$, 2.846, $P<0.001$ ), went out for prenatal examination (OR
$=5.766,95 \%$ CI: $1.064,2.440, P<0.001)$, wanted to selfmonitor during pregnancy but did not know how to do it $(\mathrm{OR}=4.559,95 \%$ CI: 0.285, 2.750, $P=0.016$ ), believed that they should be strictly isolated at home and cancel prenatal examinations (OR $=4.721,95 \%$ CI: $0.624,2.481$, $P=0.001)$, and expected to receive pregnancy healthcare through teleconsultation services $(\mathrm{OR}=2.330,95 \% \mathrm{CI}$ : $0.330,1.361, P=0.001$ ) showed a higher risk of anxiety. Nevertheless, pregnant Zhuang women who were 22-35 years old $(\mathrm{OR}=0.283,95 \% \mathrm{CI}:-2.116,-0.407, P=0.004)$, undergraduate-educated (OR $=0.287,95 \%$ CI: -1.934 ,$0.565, P<0.001$ ), and in their second trimester (OR $=0.273$, 95\% CI: $-1.868,-0.730, P<0.001)$ were less likely to suffer from anxiety.

\section{Discussion}

The maintenance of pregnant women's mental health plays a significant role in the health outcomes of the mother and fetus. This study found that the psychological status and behavior of minority pregnant women were considerably affected by the COVID-19 pandemic and that their emotional symptoms during pregnancy had complex multi-factor causes, which require extensive attention and support from society.

The study results revealed that 164 women (36.77\%) selfreported anxiety symptoms, which was higher than the results of Liu et colleagues ${ }^{29}(24.5 \%)$ in Wuhan city in the early days of the pandemic and those of Patabendige et $\mathrm{a}^{30}$ (17.5\%) in Sri Lanka during the successful containment of the spread. This is probably related to the study population (pregnant Zhuang women) and study time (the most difficult moment in fighting the COVID-19 pandemic). The high prevalence rate might indicate that COVID-19 has a significant negative impact on the lives and psychology of 
Table 2 Multivariate Logistic Regression Analysis of Participants' Anxiety $(\mathrm{N}=446)$

\begin{tabular}{|c|c|c|c|c|c|c|c|c|}
\hline \multicolumn{2}{|l|}{ Variables } & \multirow{3}{*}{$\begin{array}{c}\boldsymbol{\beta} \\
0.667\end{array}$} & \multirow{2}{*}{$\begin{array}{c}\text { SE } \\
0.558\end{array}$} & \multirow{2}{*}{\begin{tabular}{|l} 
Wald \\
1.426
\end{tabular}} & \multirow{2}{*}{$\begin{array}{c}\text { P-value } \\
0.232\end{array}$} & \multirow{2}{*}{$\begin{array}{l}\text { OR } \\
1.948\end{array}$} & \multicolumn{2}{|c|}{$95 \% \mathrm{Cl}$} \\
\hline & & & & & & & & \\
\hline Age (years) & Under 22 & & & & & & $\begin{array}{l}\text { Lower } \\
-0.428\end{array}$ & $\begin{array}{c}\text { Upper } \\
1.761\end{array}$ \\
\hline & $22-35$ & $-1.26 \mid$ & 0.436 & 8.369 & $0.004 *$ & 0.283 & -2.116 & -0.407 \\
\hline & Over $35^{\mathrm{a}}$ & - & - & - & - & 1.000 & - & - \\
\hline \multirow[t]{3}{*}{ Educational background } & High school or below & -0.160 & 0.357 & 0.201 & 0.654 & 0.852 & -0.861 & 0.540 \\
\hline & Undergraduate & -1.250 & 0.349 & 12.806 & $0.000 *$ & 0.287 & -1.934 & -0.565 \\
\hline & Postgraduate $^{\mathrm{a}}$ & - & - & - & - & 1.000 & - & - \\
\hline \multirow[t]{2}{*}{ Annual household income } & $\leq \$ 7,000$ & 0.878 & 0.284 & 9.528 & $0.002 *$ & 2.406 & 0.320 & 1.435 \\
\hline & $>\$ 7,000^{\mathrm{a}}$ & - & - & - & - & 1.000 & - & - \\
\hline \multirow[t]{3}{*}{ Trimester } & First trimester & -0.606 & 0.434 & 1.947 & 0.163 & 0.545 & -1.458 & 0.245 \\
\hline & Second trimester & -1.299 & 0.290 & 20.000 & $0.000 *$ & 0.273 & -1.868 & -0.730 \\
\hline & Third trimester ${ }^{a}$ & - & - & - & - & 1.000 & - & - \\
\hline \multirow[t]{2}{*}{ Parity } & Primiparous & 1.965 & 0.450 & 19.097 & $0.000 *$ & 7.135 & 1.084 & 2.846 \\
\hline & Multiparous ${ }^{\mathrm{a}}$ & - & - & - & - & 1.000 & - & - \\
\hline \multirow{3}{*}{$\begin{array}{l}\text { Primary reason for going } \\
\text { out }\end{array}$} & None & 0.093 & 0.422 & 0.048 & 0.826 & 1.097 & -0.734 & 0.920 \\
\hline & Prenatal examination & 1.752 & 0.351 & 24.923 & $0.000 *$ & 5.766 & 1.064 & 2.440 \\
\hline & $\begin{array}{l}\text { Shopping or visiting relatives and friends or } \\
\text { other reasons }\end{array}$ & - & - & - & - & 1.000 & - & - \\
\hline \multirow{3}{*}{$\begin{array}{l}\text { Self-monitoring during } \\
\text { pregnancy }\end{array}$} & Can and do & 0.447 & 0.618 & 0.525 & 0.469 & 1.564 & -0.763 & 1.658 \\
\hline & Want, but do not know how to do & 1.517 & 0.629 & 5.822 & $0.016 *$ & 4.559 & 0.285 & 2.750 \\
\hline & Do not care ${ }^{\mathrm{a}}$ & - & - & - & - & 1.000 & - & - \\
\hline \multirow[t]{2}{*}{$\begin{array}{l}\text { Attitude toward prenatal } \\
\text { examination }\end{array}$} & $\begin{array}{l}\text { Determinedly stayed at home and canceled } \\
\text { prenatal examinations }\end{array}$ & 1.552 & 0.474 & 10.738 & $0.001 *$ & 4.721 & 0.624 & 2.481 \\
\hline & $\begin{array}{l}\text { Necessary, attended timely or temporarily } \\
\text { postponed }{ }^{\text {a }}\end{array}$ & - & - & - & - & 1.000 & - & - \\
\hline \multirow{3}{*}{$\begin{array}{l}\text { Expected access to } \\
\text { pregnancy healthcare }\end{array}$} & Regular obstetric clinic visits & -0.428 & 0.415 & 1.064 & 0.302 & 0.652 & $-1.24 \mid$ & 0.385 \\
\hline & Teleconsultation services & 0.846 & 0.263 & 10.345 & $0.00 I^{*}$ & 2.330 & 0.330 & $1.36 \mid$ \\
\hline & Home visits by obstetrician ${ }^{\mathrm{a}}$ & - & - & - & - & 1.000 & - & - \\
\hline
\end{tabular}

Notes: *Statistically significant $(P<0.05)$; ${ }^{a}$ represent reference group.

Abbreviation: SE, standard error, OR, odds ratio, $\mathrm{Cl}$, confidential interval.

pregnant women. Although there is limited information on the assessment and management of vertical transmission of COVID-19 in pregnant women, ${ }^{19,31}$ the dramatic increase in confirmed cases would definitely cause irritability and anxiety. ${ }^{32}$ Previous studies have also confirmed an increase in fear among pregnant women around the world regarding physical condition, economic status, and daily activity arrangement with limited resources and social distancing policies. ${ }^{33}$ Although there is no evidence regarding SARS$\mathrm{CoV}-2$ infection and death cases among ethnic groups in China, it has been reported that American minorities are seriously affected by COVID-19. ${ }^{34}$ The infection rate and mortality of COVID-19 in counties with African American majorities were three and six times higher than those in white counties. ${ }^{35}$ Minority communities may be affected by chronic medical conditions and lower access to health services, or by less favorable living and working conditions, which makes them vulnerable to worse outcomes. Thus, efforts to develop strategies to identify, screen, prevent, and manage pregnancy anxiety disorders among ethnic minority pregnant women are necessary to cope with the two-fold challenge of the epidemic and pregnancy.

This study found that pregnancy-related factors and COVID-19-related problems were important driving factors for anxiety scores in Zhuang pregnant women. Multivariate logistic regression analysis showed that pregnant Zhuang 
women whose maternal age was $22-35$ years were less likely to have anxiety disorders, which is inconsistent with the results of other studies showing that maternal age is positively associated with anxiety in pregnancy, ${ }^{36}$ possibly because young pregnant women may lack the competence and knowledge of how to take care of themselves and their babies during pregnancy because of their physical and psychological immaturity. However, older women over 35 face some risks of pregnancy failure and increase the risk of fetal chromosomal abnormalities, ${ }^{37}$ which result in elevated psychological symptoms. In addition to maternal age, pregnant women with undergraduate education were less likely to suffer from anxiety disorders. Although there is no consensus on the impact of education level in current studies, ${ }^{38,39}$ education indeed has different effects on individual coping styles in different stressors. During the COVID-19 pandemic, global economy was dramatically affected. Social distancing, self-isolation, and closure of shops have reduced labor in all sectors and lead to mass unemployment. ${ }^{40}$ Because of the increasing costs of having a baby, pregnant Zhuang women with lower annual family incomes might worry about family economic conditions. This finding is supported by other studies ${ }^{41,42}$ that revealed that low income and material difficulties may affect the mental health of pregnant women. This study also revealed that pregnant women in the first and third trimesters tended to have higher anxiety than did those in the second trimester, which mirrors the results of van de Loo and colleagues ${ }^{43}$ in the Netherlands and Soto-Balbuena et al in the USA. ${ }^{44}$ The second trimester seems to be a relatively stable period in terms of mental health. Primiparity is also a risk factor for the high prevalence of anxiety, in agreement with previous findings. ${ }^{45,46}$ Primiparous women have little parenting experience and lack confidence in becoming mothers. Previous studies have reported that the self-efficacy score in neonatal care among primiparous women is generally lower than that of multiparous women. ${ }^{47}$ In addition, primiparous women usually have significantly higher levels of fear of childbirth than multiparous women. ${ }^{48}$ Thus, we need to be aware that poorer, primiparous Zhuang women in the first or third trimester may need more medical and information support.

The results of this survey revealed that during one month, from January 23 to February 23, 2020, 35.43\% of pregnant women had never gone out, which is consistent with the findings of Corbett and colleagues ${ }^{8}$ findings that $35.2 \%$ of pregnant women self-isolated to avoid developing the disease. Compared with pregnant women who had gone out shopping or visiting relatives, those who went out only for prenatal examinations had a relatively higher risk of anxiety. This might indicate that visiting and recreational activities during pregnancy could help pregnant women relieve their psychological stress. Self-monitoring during pregnancy has been proven to be an effective maternal and fetal management strategy. ${ }^{49}$ This study shows that the majority (93.27\%) of pregnant women wanted to conduct self-monitoring during pregnancy, but over one-third did not know how to do it. Pregnant women who were unable or afraid to do so were more likely to have anxiety disorders. This may be associated with the dilemma between the expectation of self-monitoring to ensure good pregnancy outcomes and limited maternal competence and skills in pregnancy care. Regarding their attitude toward prenatal examination, most of the pregnant women (68.83\%) considered postponing or temporarily canceling prenatal examinations. This attitude may stem from the fear of human-to-human virus transmission and possible infection risk on the way to medical institutions and during routine pregnancy examination, although prenatal examination is essential for a healthy pregnancy. Interestingly, in this study, women who believed that they should be strictly isolated at home and cancel prenatal examinations showed higher anxiety risk than did those who believed that prenatal examinations were necessary, must be attended regularly, or can be postponed. In the Zhuang population with a high prevalence of low-birthweight infants ${ }^{50}$ and genetic diseases, ${ }^{51}$ prenatal examination is important for them. In line with the general attitudes of ethnic minority pregnant women toward prenatal examinations, we found that the majority $(87.22 \%)$ of the respondents hoped to gain knowledge and receive prenatal examination through teleconsultation services and home visits by obstetricians. However, these two forms of prenatal examination are not widely implemented in China, although the previous evidence has proved that the "Internet + Mobile Prenatal Examination" model has not only improved the maternal check-up experience but also promoted a rational redistribution of medical resources. ${ }^{52}$ The Zhuang population, which differs from other Chinese populations in terms of race, living environment, diet, and culture, faced a shortage and an unbalanced allocation of medical and health resources. ${ }^{53}$ Online obstetric assistance or a community doctor on-site service is urgently needed to fill this gap.

\section{Limitations}

This study has several limitations. First, the single-center design and possible selection bias limit the generalization of the results. Future research may recruit pregnant women from other ethnic groups, such as Uyghur, Dai, and Tibetan. Second, some participants may have chosen answers randomly to get 
the reward in the least possible time, although we removed the questionnaires showing answer patterns and answer times lower than two minutes, to minimize data bias. Third, the assessment of anxiety symptoms relies on self-report, although SAS is an internationally recommended screening tool and has been used in many studies on pregnant women. Fourth, regarding obstetric characteristics, some potential associated variables such as abnormal fetus, infertility history, abortion history and intention to pregnancy were not considered in this study. Further multicenter, cross-sectoral studies are needed to extend this research to other factors and assess the psychological impact of the pandemic on pregnant women and their children, especially among ethnic minorities.

\section{Conclusions}

This study reported the psychological impact of the COVID-19 pandemic on pregnant women of Zhuang ethnicity in China, which provides a unique perspective for the development of a psychological strategy. Our research results show that the prevalence $(36.77 \%)$ of anxiety symptoms in pregnant Zhuang women increased after the implementation of social distancing and quarantine policies. Furthermore, these women adapted their daily behaviors, and several risk factors for anxiety were identified. Zhuang pregnant women needed additional mental support during the COVID-19 outbreak. Multidisciplinary mental health services and culturally sensitive interventions provided by the government, community, and relevant departments are necessary.

\section{Data Sharing Statement}

Data will be provided under formal request to the first author.

\section{Ethics Approval}

This study was approved by the Medical Ethics Committee of Xiangnan University (No. KY- 202002001). The executive committee approved the proposed project entitled "Mental Health and Related Factors of Different Populations during COVID-19 Pandemic in China" on 28 January 2020. This study was performed in accordance with the ethical standards laid down in the 1964 Declaration of Helsinki and its later amendments.

\section{Consent to Participate}

Informed consent was obtained from pregnant women before completing the questionnaire. Participants voluntarily and anonymously completed the questionnaire and were allowed to withdraw from the study at any time without any reason. After completing the investigation, they obtained 5 to 10 Chinese RMB (roughly equivalent to $0.70-1.40 \mathrm{USD}$ ) and tips on health care for pregnant women during the epidemic.

\section{Acknowledgments}

First, we would like to thank the following supporters for collecting information: Jing Ling, Department of Obstetrics, First Affiliated Hospital of Guangxi Medical University; Jinmei Meng, Department of Obstetrics, Nanning Chinese Medicine Hospital of Guangxi, and Fengming Li, Obstetrics Department of Ruikang Hospital, Guangxi University of Chinese Medicine. Second, we express our gratitude to all the participants for their valuable contributions. Third, we thank Xiangnan University for the approval and support of this study. Fourth, we thank the Education Department of the Guangxi government for providing financial and material support.

\section{Funding}

This study was sponsored by Guangxi University Young Teachers' Basic Ability Improvement Project (grant no. 2018KY0291, funding 30,000 Chinese RMB) hosted by the first author and the Hunan Social Science Achievement Evaluation Committee (grant no. XSP20YBC164) hosted by the corresponding author.

\section{Disclosure}

The authors have no conflicts of interest to declare relevant to the contents of this article.

\section{References}

1. World Health Organization. Surveillance case definitions for human infection with novel coronavirus $(\mathrm{nCoV})$ Interim guidance January 2020. Available from: https://apps.who.int/iris/bitstream/han dle/10665/330376/WHO-2019-nCoV-Surveillance-v2020.1-eng.pdf. Accessed March 31, 2021.

2. Global Times. 25 provinces, cities, and autonomous regions activated major public health emergency primary responses; 2020. Available from: https://3w.huanqiu.com/a/c36dc8/9CaKrnKp4bG?agt=8.wap. Accessed March 31, 2021.

3. National Health Commission of the People's Republic of China Notice on strengthening community prevention and control of pneumonia infection epidemic caused by new coronavirus; 2020. Available from: http://www.nhc.gov.cn/jkj/s3577/202001/dd1e502534004a8d88 b6a10f329a3369.shtml.

4. Nath S, Ryan EG, Trevillion K, et al. Prevalence and identification of anxiety disorders in pregnancy: the diagnostic accuracy of the two-item Generalised Anxiety Disorder scale (GAD-2). BMJ Open. 2018;8(9):e023766. doi:10.1136/bmjopen-2018-023766 
5. Dennis C-L, Falah-Hassani K, Shiri R. Prevalence of antenatal and postnatal anxiety: systematic review and meta-analysis. $\mathrm{Br}$ J Psychiatry. 2017;210(5):315-323. doi:10.1192/bjp.bp.116.187179

6. Thapa SB, Mainali A, Schwank SE, Acharya G. Maternal mental health in the time of the COVID-19 pandemic. Acta Obstet Gynecol Scand. 2020;99(7):817-818. doi:10.1111/aogs.13894

7. Davenport MH, Meyer S, Meah VL, Strynadka MC, Khurana R. Moms are not ok: COVID-19 and maternal mental health. Front Global Women's Health. 2020;1:1. doi:10.3389/fgwh.2020.00001

8. Corbett GA, Milne SJ, Hehir MP, Lindow SW, O'connell MP. Health anxiety and behavioural changes of pregnant women during the COVID-19 pandemic. Eur J Obstet Gynecol Reproduct Biol. 2020;249:96-97. doi:10.1016/j.ejogrb.2020.04.022

9. Zhao X, Jiang Y, Zhao Y, et al. Analysis of the susceptibility to COVID-19 in pregnancy and recommendations on potential drug screening. Eur J Clin Microbiol Infect Dis. 2020;39(7):1209-1220. doi:10.1007/s10096-020-03897-6

10. Ravaldi C, Wilson A, Ricca V, Homer C, Vannacci A. Pregnant women voice their concerns and birth expectations during the COVID-19 pandemic in Italy. Women Birth. 2020. doi:10.1016/j. wombi.2020.07.002

11. Accortt EE, Cheadle AC, Dunkel Schetter C. Prenatal depression and adverse birth outcomes: an updated systematic review. Matern Child Health J. 2015;19(6):1306-1337. doi:10.1007/s10995-014-1637-2

12. Isgut M, Smith AK, Reimann ES, Kucuk O, Ryan J. The impact of psychological distress during pregnancy on the developing fetus: biological mechanisms and the potential benefits of mindfulness interventions. J Perinat Med. 2017;45(9):999-1011. doi:10.1515/ jpm-2016-0189

13. Tian R, Zhang X, Chen X, et al. Pregnant women's health-related behavior changes and psychological status after the peak of COVID19 outbreak in China: a cross-sectional study; 2020. DOI:10.21203/ rs.3.rs-67761/v1(preprint).

14. Yue C, Lie C, Wang J, et al. Association between social support and anxiety among pregnant women in the third trimester during the coronavirus disease 2019 (COVID-19) epidemic in Qingdao, China: the mediating effect of risk perception. Int $J$ Soc Psychiatry. 2020:20764020941567.

15. Li J, Liu M. The status quo and characteristics of changes in the ethnic minority population. N.W. J Ethnol. 2019;4:120-137.

16. Yuan X, Liu H, Liu X, et al. Fertility levels and trends in China's ethnic minority provinces, 2006-2016: based on 2017 China fertility survey. Popul Res. 2019;43(2):61-69.

17. He D, Zhang X, Zhuang Y, Wang Z, Yang S. China fertility status report, 2006-2016: an analysis based on 2017 China fertility survey. Popul Res. 2018;42(6):35-45.

18. Zhang Y, He H, Wu F, et al. Analysis on the status quo of obstetric service capacity of medical and health institutions in minority areas in Sichuan Province. China Matern Child Health. 2015;30 (7):994-996.

19. Fakari FR, Simbar M. Coronavirus pandemic and worries during pregnancy, a letter to editor. Arch Acad Emerg Med. 2020;8(1):e21.

20. Chen L, Li Q, Zheng D, et al. Clinical characteristics of pregnant women with COVID-19 in Wuhan, China. $N$ Engl J Med. 2010;382 (25):e100. doi:10.1056/NEJMc2009226

21. Schwartz DA. An analysis of 38 pregnant women with COVID-19, their newborn infants, and maternal-fetal transmission of SARS-CoV-2: maternal coronavirus infections and pregnancy outcomes. Arch Pathol Lab Med. 2020;144(7):799-805. doi:10.5858/arpa.2020-0901-SA

22. Statistics Bureau of Guangxi Zhuang Autonomous Region. Statistical bulletin of national economic and social development of Guangxi Zhuang autonomous region in 2019; 2019. Available from: http://tjj. gxzf.gov.cn/tjsj/tjgb/qqgb/t2381676.shtml. Accessed March 31, 2021.

23. Lwanga SK, Lemeshow S. Sample size determination in health studies: a practical manual. Geneva: World Health Organization; 1991.
24. Sinesi A, Maxwell M, O’Carroll R, Cheyne H. Anxiety scales used in pregnancy: systematic review. BMJ Psych Open. 2019;5:e5.

25. Wang Z, Chi Y. Chinese version of Zung's self-rating anxiety scale. Shanghai Arch Psychiatry. 1984;2:73-74.

26. Zung WW. A rating instrument for anxiety disorders. Psychosomatics. 1971;12(6):371-379. doi:10.1016/S0033-3182(71)71479-0

27. Ma X, Wang Y, Hu H, Tao XG, Zhang Y, Shi H. The impact of resilience on prenatal anxiety and depression among pregnant women in Shanghai. J Affect Disord. 2019;250:57-64. doi:10.1016/j. jad.2019.02.058

28. Wang W. Self-rating anxiety scale (SAS). In: Wang X, Wang X, $\mathrm{Ma} \mathrm{H}$, editors. Handbook of Mental Health Assessment Scale. 2019:477-478.

29. Liu X, Chen M, Wang Y, et al. Prenatal anxiety and obstetric decisions among pregnant women in Wuhan and Chongqing during the COVID-19 outbreak: a cross-sectional study. BJOG. 2020;127 (10):1229-1240. doi:10.1111/1471-0528.16381

30. Patabendige M, Gamage MM, Weerasinghe M, Jayawardane A. Psychological impact of the COVID-19 pandemic among pregnant women in Sri Lanka. Int J Gynecol Obstet. 2020;151(1):150-153. doi:10.1002/ijgo.13335

31. Luo Y, Yin K. Management of pregnant women infected with COVID-19. Lancet Infect Dis. 2020;20(5):513-514. doi:10.1016/ S1473-3099(20)30191-2

32. Saccone G, Florio A, Aiello F, et al. Psychological impact of coronavirus disease 2019 in pregnant women. Am J Obstet Gynecol. 2020;223(2):293-295. doi:10.1016/j.ajog.2020.05.003

33. Kajdy A, Feduniw S, Ajdacka U, et al. Risk factors for anxiety and depression among pregnant women during the COVID-19 pandemic: a web-based cross-sectional survey. Medicine. 2020;99(30):e21279. doi:10.1097/MD.0000000000021279

34. Dyer O. Covid-19: black people and other minorities are hardest hit in US. BMJ. 2020;369:m1483. doi:10.1136/bmj.m1483

35. Doumas M, Patoulias D, Katsimardou A, Stavropoulos K, Imprialos K, Karagiannis A. COVID19 and increased mortality in African Americans: socioeconomic differences or does the renin angiotensin system also contribute? J Hum Hypertens. 2020;34(11):764-767.

36. Huang MZ, Kao CH, Lin KC, Hwang JL, Puthussery S, Gau ML. Psychological health of women who have conceived using assisted reproductive technology in Taiwan: findings from a longitudinal study. BMC Womens Health. 2019;19(1):97. doi:10.1186/s12905-019-0801-7

37. Ayaz R, Hocaoğlu M, Günay T, Devrim Yardımcı O, Turgut A, Karateke A. Anxiety and depression symptoms in the same pregnant women before and during the COVID-19 pandemic. J Perinat Med. 2020;48(9):965-970. doi:10.1515/jpm-2020-0380

38. Zhang Y, Muyiduli X, Wang S, et al. Prevalence and relevant factors of anxiety and depression among pregnant women in a cohort study from south-east China[J]. J Reprod Infant Psychol. 2018;36 (5):519-529. doi:10.1080/02646838.2018.1492098

39. Moyer CA, Compton SD, Kaselitz E, Muzik M. Pregnancy-related anxiety during COVID-19: a nationwide survey of 2740 pregnant women. Arch Womens Ment Health. 2020;23(6):757-765. doi:10.1007/s00737-020-01073-5

40. Nicola M, Alsafi Z, Sohrabi C, et al. The socio-economic implications of the coronavirus and COVID-19 pandemic: a review. Int J Surg. 2020;78:185-193. doi:10.1016/j.ijsu.2020.04.018

41. Katz J, Crean HF, Cerulli C, Poleshuck EL. Material hardship and mental health symptoms among a predominantly low income sample of pregnant women seeking prenatal care. Matern Child Health J. 2018;22(9):1360-1367. doi:10.1007/s10995-018-2518-x

42. Bödecs T, Szilágyi E, Cholnoky P, et al. Prevalence and psychosocial background of anxiety and depression emerging during the first trimester of pregnancy: data from a Hungarian population-based sample. Psychiatr Danub. 2013;25(4):352-358. 
43. van de Loo KFE, Vlenterie R, Nikkels SJ, et al. Depression and anxiety during pregnancy: the influence of maternal characteristics[J]. Birth. 2018;45(4):478-489. doi:10.1111/ birt. 12343

44. Soto-Balbuena C, Rodriguez MD, Escudero Gomis AI, Ferrer Barriendos FJ, Le HN, Pmb-Huca G. Incidence, prevalence and risk factors related to anxiety symptoms during pregnancy. Psicothema. 2018;30(3):257-263. doi:10.7334/psicothema2017.379

45. Nakamura Y, Okada T, Morikawa M, et al. Perinatal depression and anxiety of primipara is higher than that of multipara in Japanese women. Sci Rep. 2020;10(1):17060. doi:10.1038/s41598-02074088-8

46. Tang X, Lu Z, Hu D, Zhong X. Influencing factors for prenatal stress, anxiety and depression in early pregnancy among women in Chongqing, China. J Affect Disord. 2019;253:292-302. doi:10.1016/ j.jad.2019.05.003

47. Brunton R, Simpson N, Dryer R. Pregnancy-related anxiety, perceived parental self-efficacy and the influence of parity and age. Int J Environ Res Public Health. 2020;17(18):6709. doi:10.3390/ijerph17186709
48. Mazúchová L, Škodová Z, Kelčíková S, Rabárová A. Factors associated with childbirth-related fear among Slovak women. Cent Eur J Nurs Midwifery. 2017;8(4):742-748. doi:10.15452/CEJNM.2017.08.0027

49. El-Sayed HE, Hassan SI, Aboud SA, Ibrahim AA. Effect of women self monitoring of fetal kicks on enhancing their general health status. Am J Nurs Res. 2018;6(3):117-124.

50. Long J, Qiu X, Zeng X, et al. Analysis on the risk factors for low birth weight infants of Zhuang ethnicity in Pingguo and Debao County of Guangxi Province. Chin J Dis Control Prev. 2017;21 (6):558-561.

51. Shi M, Liu F, Xu L, et al. Analysis of deafness-related gene mutations in 23 nonsyndromic hearing impairment families in Guangxi Zhuang Autonomous Region. J Clin Otorhinolaryngol Head Neck Surg. 2017;31(4):277-283.

52. Zhou Q, Luo Q, Zeng $\mathrm{H}$, et al. Innovative practice of "Internet +Mobile Antenatal Care". China Digit Med. 2019;14(12):114-117.

53. Qin J, Peng R, Yao Y, et al. Study on the balanced development of health resources in 14 cities of Guangxi Zhuang autonomous region. Soft Sci Health. 2019;33(2):49-54.
Risk Management and Healthcare Policy

\section{Publish your work in this journal}

Risk Management and Healthcare Policy is an international, peerreviewed, open access journal focusing on all aspects of public health, policy, and preventative measures to promote good health and improve morbidity and mortality in the population. The journal welcomes submitted papers covering original research, basic science, clinical \& epidemiological studies, reviews and evaluations,

\section{Dovepress}

guidelines, expert opinion and commentary, case reports and extended reports. The manuscript management system is completely online and includes a very quick and fair peer-review system, which is all easy to use. Visit http://www.dovepress.com/testimonials.php to read real quotes from published authors. 